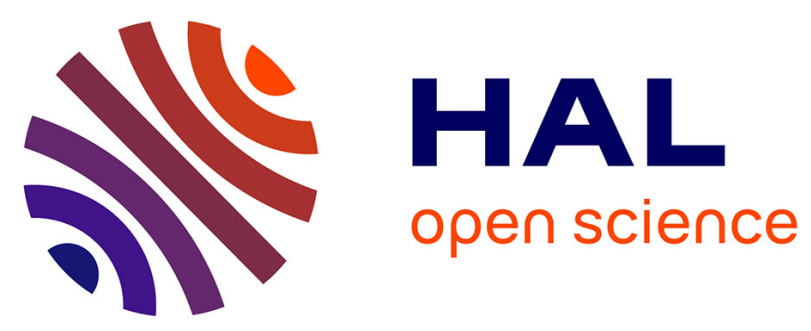

\title{
Development of a Conceptual Architecture for the Energy Management of Building Ecosystems
}

Filipa Ferrada, Ana Inês Oliveira, João Rosas, Patrícia Macedo, Ricardo

Almeida, Luis M. Camarinha-Matos

\section{- To cite this version:}

Filipa Ferrada, Ana Inês Oliveira, João Rosas, Patrícia Macedo, Ricardo Almeida, et al.. Development of a Conceptual Architecture for the Energy Management of Building Ecosystems. 20th Working Conference on Virtual Enterprises (PRO-VE), Sep 2019, Turin, Italy. pp.418-430, 10.1007/978-3030-28464-0_36. hal-02478739

\section{HAL Id: hal-02478739 \\ https://hal.inria.fr/hal-02478739}

Submitted on 14 Feb 2020

HAL is a multi-disciplinary open access archive for the deposit and dissemination of scientific research documents, whether they are published or not. The documents may come from teaching and research institutions in France or abroad, or from public or private research centers.
L'archive ouverte pluridisciplinaire HAL, est destinée au dépôt et à la diffusion de documents scientifiques de niveau recherche, publiés ou non, émanant des établissements d'enseignement et de recherche français ou étrangers, des laboratoires publics ou privés. 


\title{
Development of a Conceptual Architecture for the Energy Management of Building Ecosystems
}

\author{
Filipa Ferrada ${ }^{1,2}$, Ana Inês Oliveira ${ }^{1,2}$, João Rosas ${ }^{1,2}$, Patrícia Macedo ${ }^{2,3}$, Ricardo \\ Almeida $^{1,2}$ and Luis M. Camarinha-Matos ${ }^{1,2}$ \\ ${ }^{1}$ Faculty of Sciences and Technology, Nova University of Lisbon, Caparica, Portugal \\ ${ }^{2}$ Uninova Institute, Centre of Technology and Systems (CTS), Portugal \\ \{faf, aio, jrosas, cam\}@uninova.pt, rdl.almeida@campus.fct.unl.pt \\ ${ }^{3}$ ESTSetúbal, Polytechnic Institute of Setúbal, Setúbal, Portugal \\ patricia.macedo@estsetubal.ips.pt
}

\begin{abstract}
The current environmental, social, and political pressure for more efficient use of energy led to the emergence of new legislation and directives both at National and European levels and, as a consequence, to the creation of various focused technological initiatives. In this line, several developments are being carried out to increase energy efficiency by reducing the energy consumption of buildings, costs, and carbon emissions, while providing adequate levels of comfort to the building's occupants. This work intends to contribute to this area, by proposing a conceptual architecture, based on collaborative networks of physical components/devices virtualized as services to compute and communicate information to support efficient energy management of building ecosystems. The architecture is designed considering the functional requirements, the most relevant technological challenges, and the implementation strategies.
\end{abstract}

Keywords: Energy efficiency of buildings, Conceptual architecture, Building ecosystem.

\section{Introduction}

One of the current topics of attention in our society is the large energy consumption and its self-sustainability, making it clear that it is necessary to increase energy efficiency, reducing energy consumption and carbon emissions in this sector [1][2]. In this context, it becomes essential to address these problems in industry and service buildings (public and private), checking the main energy efficiency gaps, and intervening to rectify the main issues in building's equipment that contribute to inadequate energy consumptions.

On the other hand, the need for environmental comfort in buildings often comes into conflict with the awareness of reducing energy consumption, creating the need to find solutions that integrate the comfort of the occupants, the indoor air quality (IAQ) and efficient energy management, and consequently, the level of carbon emissions. Some building energy management systems (BEMS) already consider these issues, 
nevertheless the costs for implementing such systems are still quite high and with no capacity to scale or adapt. Environmental comfort in buildings requires a transformation of BEMS to accomplish some objectives, namely, energy efficiency and occupants' comfort, scalability and interoperability of systems, and reduced cost of implementation. In addition, as sub-systems / components become more intelligent, embedding higher computational power, a promising approach is to consider the building as an ecosystem of collaborative sub-systems.

In this context, a conceptual architecture for building energy management with low implementation cost, high adaptability, versatility, and easy maintenance is proposed and described. This architecture, which is based on collaborative networks of smart physical components/devices, considers the management and implementation of a set of previously defined environmental quality parameters and energy performance indicators which, in conjunction with machine learning capabilities, supports efficient energy decision-making leading to effective energy management. The approach corresponds to a case of collaborative cyber-physical system and is aligned with the premises of Industry 4.0.

This work is developed in the context of the project AMBIOSENSING Autonomous and Intelligent Systems for Energy Saving,

The remainder of this paper is structured as follows: section 2 presents the current research trends in the energy efficiency area; in section 3 an overview of business requirements of the system is presented with the identified functional and nonfunctional requirements along with a use case diagram; section 4 presents the proposed conceptual architecture; in section 5 a discussion regarding the implementation aspects is provided, and finally section 6 concludes and highlights future work.

\section{Energy Efficiency Research Challenges}

\subsection{Regulatory Framework}

The topic of energy efficiency has become increasingly relevant in Europe and its Member States, which have been working on updating and harmonizing the main European policy instruments in this area. The buildings sector in Europe accounts for around $40 \%$ of total energy consumption [3]. However, it is estimated that more than $50 \%$ of this consumption can be reduced by implementing energy efficiency measures, which can represent an annual reduction of $\mathrm{CO} 2$ emissions to the atmosphere of around 400 million tons. This represents almost the whole of the European Union's (EU) commitment under the Kyoto Protocol [4], [5]. One of the short-term measures to put in practice the reduction of energy consumption relies on renovating existing buildings. Annual investments in building renovation will have to triple to reach the $32.5 \%$ energy efficiency target by 2030 .

In addition, energy efficiency is one of the most cost-effective means of supporting the transition to a carbon-neutral economy and a key policy for implementing the Paris Agreement [6] to try to limit GHG emissions to a level that limits global temperature increase to less than $1.5^{\circ} \mathrm{C}$ and preventing catastrophic and irreparable effects on ecosystems. While environmental commitments are being met, energy efficiency also reduces energy bills and import dependency. 
Energy efficiency is thus one of the pillars of carbon neutrality strategies of the European Union. In this context, the European Commission (EC) adopted on 28 November 2018 its strategic vision for surpassing the 2030 climate target and to set eyes on achieving a net zero carbon economy by 2050 , through what it called a fair transition involving all sectors of the economy [7]. The transition to a carbon-neutral economy is possible from a technological, economic and social points of view, but requires a profound societal and economic transformation within a generation.

In this context, the Directive (EU) 2018/844 of the European Parliament and of the Council [8] establishes a set of measures and guidelines, some of which are briefly highlighted here:

- Promote research and testing of new solutions to improve the energy performance of buildings;

- Consider the installation of self-regulating devices in existing buildings;

- Use of smart readiness indicators for intelligent technologies, namely in measuring the capacity of buildings to use information and communication technologies and electronic systems to adapt the operation of buildings to the needs of the occupants;

- Provide effective inspections of the central heating systems and air-conditioning systems, including those which are combined with ventilation systems, to obtain better energy efficiency results;

- Provide new buildings with self-regulating devices to be able to regulate the comfort conditions in each room of buildings and facilities, autonomously.

The architecture proposed in this work takes the above policies and measures into consideration.

\subsection{Building Energy Management Systems}

The building energy management systems (BEMS) are responsible for monitoring and controlling the environment in commercial, industrial and institutional facilities, ensuring operational performance as well as the comfort and safety of buildings' occupants. These systems usually use computer networks to monitor and control the energy of services and equipment in buildings, such as Heating, Ventilation, and Air Conditioning (HVAC) systems, lighting systems, energy systems, pumping systems, among others [9].

BEMS are often confused with Building Management Systems (BMS) and Building Automation and Control Systems (BACS), however, in practice they are not the same. BMSs can be used to monitor and control a wide range of existing building systems including fire, smoke detection, alarms, CCTV, security and access control, elevators, among others, while the BACS focus on management and control and automation processes. On its turn, BEMS are specifically related to energy systems. They can, however, be connected to one or both systems if necessary. BEMS can combine data from all systems to provide better and more accurate visualization of energy use and consumption.

BEMSs provides real-time remote monitoring and integrated control of a wide range of connected systems and devices, providing information on modes of operation, energy use, environmental conditions, maintenance, among others, including measurement, notification trend and diagnosis of unnecessary energy use; performance 
optimization by setting operating hours, set-points, among others; preventive and corrective actions and building comfort [8]. BEMSs also allow the recording of performance history, enabling performance benchmarking about other buildings or locations. The best energy and comfort management systems in buildings should also add external information such as service's billing, electricity network, and meteorological data.

Energy Monitoring Systems. These are systems capable of measuring the consumption of one or more electrical equipment in a building. They emerge from the need to reduce unnecessary energy consumption to achieve better energy efficiency. These systems quantify and identify the consumption of energy in real time of an area or location and determine the associated economic impact. They also provide the identification of abnormal consumption, facilitating its correction.

There are several energy consumption monitoring systems on the market, each with its characteristics, but not all of them respond to the same type of needs. Some are more dedicated to the analysis of electrical parameters while others are limited to reading remote data. Table 1 presents a comparison of various monitoring systems according to the identified characteristics.

Table 1. Comparison of various energy monitoring systems

\begin{tabular}{|l|c|c|c|c|c|c|}
\hline & $\begin{array}{c}\text { ViGIE } \\
2.0 \\
{[10]}\end{array}$ & $\begin{array}{c}\text { Wi- } \\
\text { LEM } \\
{[11]}\end{array}$ & $\begin{array}{c}\text { SiteSage } \\
{[12]}\end{array}$ & $\begin{array}{c}\text { Optimal } \\
\text { Monitoring } \\
\text { System [13] }\end{array}$ & $\begin{array}{c}\text { EMC } \\
{[14]}\end{array}$ & $\begin{array}{c}\text { BeEner } \\
\text { gy [15] }\end{array}$ \\
\hline Automation functionality & $\checkmark$ & $\checkmark$ & & $\checkmark$ & $\checkmark$ & $\checkmark$ \\
\hline $\begin{array}{l}\text { Multi-parameters } \\
\text { monitoring }\end{array}$ & $\checkmark$ & $\checkmark$ & $\checkmark$ & $\checkmark$ & $\checkmark$ & \\
\hline Reporting & $\checkmark$ & & & $\checkmark$ & $\checkmark$ & $\checkmark$ \\
\hline $\begin{array}{l}\text { Cost and consumption } \\
\text { detailed analysis }\end{array}$ & $\checkmark$ & & $\checkmark$ & $\checkmark$ & $\checkmark$ & $\checkmark$ \\
\hline Wi-Fi communication & $\checkmark$ & $\checkmark$ & $\checkmark$ & $\checkmark$ & $\checkmark$ & \\
\hline Alerts generation & $\checkmark$ & & $\checkmark$ & $\checkmark$ & $\checkmark$ & \\
\hline $\begin{array}{l}\text { Use of energy in multiple } \\
\text { sites benchmarking }\end{array}$ & & & $\checkmark$ & $\checkmark$ & $\checkmark$ & \\
\hline Historical data & & $\checkmark$ & $\checkmark$ & $\checkmark$ & $\checkmark$ & $\checkmark$ \\
\hline Centralized management & & $\checkmark$ & & $\checkmark$ & $\checkmark$ & \\
\hline $\begin{array}{l}\text { Proprietary (integration } \\
\text { only with own equipment) }\end{array}$ & $\checkmark$ & $\checkmark$ & & $\checkmark$ & $\checkmark$ & $\checkmark$ \\
\hline
\end{tabular}

Control and Automation Systems in Buildings. Also known as building automation systems, these systems have undoubtedly led to the general specifications of monitoring and measurement systems. These control systems are generally centralized and integrate software and hardware networks that monitor and control indoor weather conditions. The operational performance of buildings, as well as the safety and comfort of occupants, is usually ensured by these control systems.

Existing building control systems can be roughly categorized as conventional controllers and intelligent controllers. The conventional ones focus essentially on energy consumption, being the best known the on/off controllers (better known as thermostats), and the P, PI and PID controllers [10], [11], [16]. On its turn, the intelligent controllers besides the energy consumption, also consider the comfort of the occupants in buildings. Examples of intelligent controllers are: methods based on 
learning that include artificial intelligence, fuzzy systems and systems of neural-fuzzy networks with conventional controllers, adaptive neural-fuzzy inference systems (ex. ANFIS - Adaptative Neural Fuzzy Inference System), etc. [8], [12]; models based on predictive control techniques (MPC), which follow the principles of classical controllers [13]-[15]; and control models based on agents [17], [18].

A more in-depth analysis has been carried out about the products supplied by various manufacturers. This study was done by selecting the products that have functionalities relevant to energy efficiency. The information was obtained online, through the manufacturer's commercial web pages, as well as from product/solution brochures, when available. This was a difficult task given the natural and understandable resistance from the manufacturers to reveal the most technical details of their products. In this sense, some technical information may be omitted due to lack of available information. Nevertheless, the solutions and products analyzed provide a wide range of alternatives for the control and energy optimization of buildings. Due to space constraints, the detailed analysis is not presented. However, it can be said that the predictive control models have gained popularity, especially in recent works, being the most common model used by most of the reviewed products and literature. Predictive control can be explained having into account that this type of model, grouped under the name of Model Predictive Control (MPC), consistently have better performance levels than other optimization and control algorithms. These models have proved their value with their ability to adapt to: (i) unpredictable disturbances or errors in prediction; (ii) exploration of the thermal mass of a building; (iii) consideration for variable energy prices, and; (iv) ability to protect the load against voltage peaks. New generations of intelligent buildings should not only take into account aspects such as space occupation prediction and meteorological conditions but also be sufficiently adaptable to maximize the use of renewable energy sources, energy storage units and program their consumption around periods of low energy cost [19].

Currently, some commercial building energy management systems [20], [21] already started to cover some of the intelligent aspects described above, nevertheless, they are still in an embryonic stage. Moreover, the costs associated to these systems are still quite high and with no capacity to scale or adapt. In this line, the proposed architecture aims to cover intelligent techniques aspects, such as optimization algorithms, with low implementation cost, high adaptability and scalability, and easy maintenance.

\section{Requirements in Energy Management of Building Ecosystem}

The identification of requirements, from the end user's point of view, is a key point in the process of design and development of a system. For the specific case, to identify the main functionalities that the system should provide, a set of potential usage scenario have been foreseen for its usage, namely: a factory of cosmetic production, a greenhouse for flower production, an anchor store, and a call center. Table 2 presents the identification of the main functional requirements of the system, while Table 3 shows the main non-functional requirements. 
Table 2. Identification of the main functional requirements of the system

\begin{tabular}{|l|l|}
\hline $\begin{array}{l}\text { Functional requirements (FR) } \\
\text { [requirements related to technical functionalities or system performance] }\end{array}$ \\
\hline FR1 & $\begin{array}{l}\text { The system must be able to define the environmental variables to be controlled: } \\
\text { CO2, Humidity, Temperature, Particles, COV, and Brightness, etc. }\end{array}$ \\
\hline FR2 & $\begin{array}{l}\text { The system shall allow the configuration of several sensors and the connection of } \\
\text { the sensors to environmental variables. }\end{array}$ \\
\hline FR3 & $\begin{array}{l}\text { The system must allow configuration and connections of actuators and actuation } \\
\text { systems (valves, switches, blades, etc...). }\end{array}$ \\
\hline FR4 & The system must allow integrated control of environmental variables. \\
\hline FR5 & $\begin{array}{l}\text { The system must allow the replacement of sensors or actuators while the system is } \\
\text { running. }\end{array}$ \\
\hline FR6 & $\begin{array}{l}\text { The system must allow energy usage profiles to be defined and its control should be } \\
\text { adjusted accordingly. }\end{array}$ \\
\hline FR7 & $\begin{array}{l}\text { The system shall withstand operation in automatic mode and manual mode. In } \\
\text { manual mode, the energy profile is selected manually (RF6), in automatic mode, the } \\
\text { profile is automatically selected by the system to optimize its performance. }\end{array}$ \\
\hline FR8 & $\begin{array}{l}\text { The system should allow the simulation of different energy profiles by creating } \\
\text { scenarios. }\end{array}$ \\
\hline FR9 & $\begin{array}{l}\text { The system must allow remote supervision, supporting real-time monitoring and } \\
\text { alarm configuration. }\end{array}$ \\
\hline FR10 & The system must support behavioral analysis. \\
\hline FR11 & The system must allow historical data consultation. \\
\hline FR12 & The system must support the generation of reports on its performance. \\
\hline
\end{tabular}

Table 3. Identification of the main non-functional requirements of the system

\begin{tabular}{|l|l|}
\hline $\begin{array}{l}\text { Non-functional requirements (NFR) } \\
\text { [requirements related to the description of system performance]. }\end{array}$ \\
\hline NFR1 & Availability: The system must be operational at least 90\% of the time. \\
\hline NFR2 & $\begin{array}{l}\text { Accessibility: The system must provide user interfaces for mobile and non-mobile } \\
\text { devices. }\end{array}$ \\
\hline NFR3 & $\begin{array}{l}\text { Performance: the system should allow efficient intelligent supervision and } \\
\text { optimization of energy efficiency considering the comfort of the occupants. }\end{array}$ \\
\hline NFR4 & $\begin{array}{l}\text { Performance: the system must efficiently support the management of large and } \\
\text { Nomplex data sets. }\end{array}$ \\
\hline NFR6 & $\begin{array}{l}\text { Maintenance: the system must have a set of processes to allow real-time monitoring, } \\
\text { with mechanisms to recover from failures/errors, such as data loss and } \\
\text { communication failures. } \\
\text { Scalability: the system must allow the introduction and removal of new } \\
\text { measurement devices and actuation systems. }\end{array}$ \\
\hline NFR7 & $\begin{array}{l}\text { Interoperability: the system must support the integration of heterogeneous systems } \\
\text { (e.g., IoT solutions, legacy systems, etc.), with different degrees of intelligence / } \\
\text { autonomy. }\end{array}$ \\
\hline NFR9 & $\begin{array}{l}\text { Cost: the implemented solution must use non-proprietary and freeware software and } \\
\text { equipment, throughout its life cycle. }\end{array}$ \\
\hline
\end{tabular}

Given the heterogeneity of all the elements in terms of energy management resources and services, the architecture for such a system should leverage solutions that enable these elements to be organized into collaborative ecosystems [23] in which they can 
understand each other, exchange information, and collaborate. Therefore, there are two main phases for such a system, including the installation and exploitation.

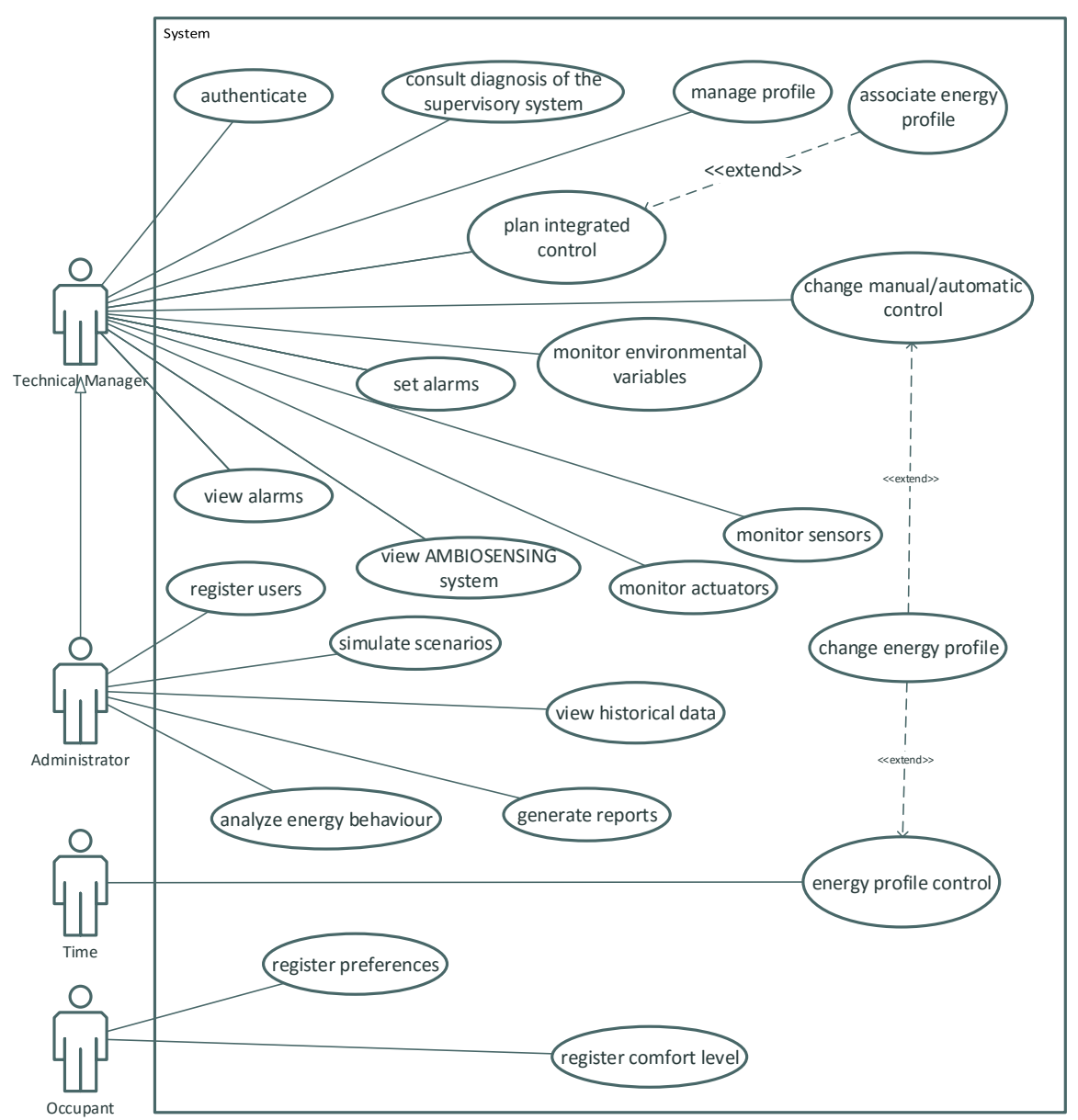

Fig. 1. Use case diagram of the exploration phase of the Ambiosensing system

For the installation phase, the main user of the system is an Installer, who will perform the entire configuration of the energy management system. There is another user, the Administrator, that is present in the whole life cycle of the system and is in charge of making the registration of all users.

In the exploration phase, different profiles of System Users can exist, namely: the Administrator, the Technical Manager, and the Occupant of the installations. The Administrator is allowed to register users and has access to the functionalities that allow global analysis of the Energy Management System (generation of reports, consultation of historical data, simulations, etc.), but also has access to all functionalities of the System available to the Technical Manager. The Technical Manager is the user 
responsible for daily operation and maintenance, being able to monitor all the controlled environmental variables and associated equipment and change the basic configurations of the energy control. The Occupant can introduce preferences into the System, as well as report his/her degree of satisfaction regarding environmental comfort. The main use cases for the exploitation phase are illustrated in Fig. 1.

\section{Conceptual Architecture}

The conceptual architecture (or high-level view) aims to show succinctly, the main elements and functionalities that make up the system architecture, regardless of any technological specificity. Based on the specification of the use cases, a conceptual architecture for the Ambiosensing system was developed as illustrated in Fig. 2. A layered architecture is proposed to identify and separate the different levels of interaction and to better manage dependencies. Each layer has a specific responsibility, being the upper layers able to use services from the lower layers, but not the opposite. Thus, in the case of the Ambiosensing System, three layers have been defined as follows below.

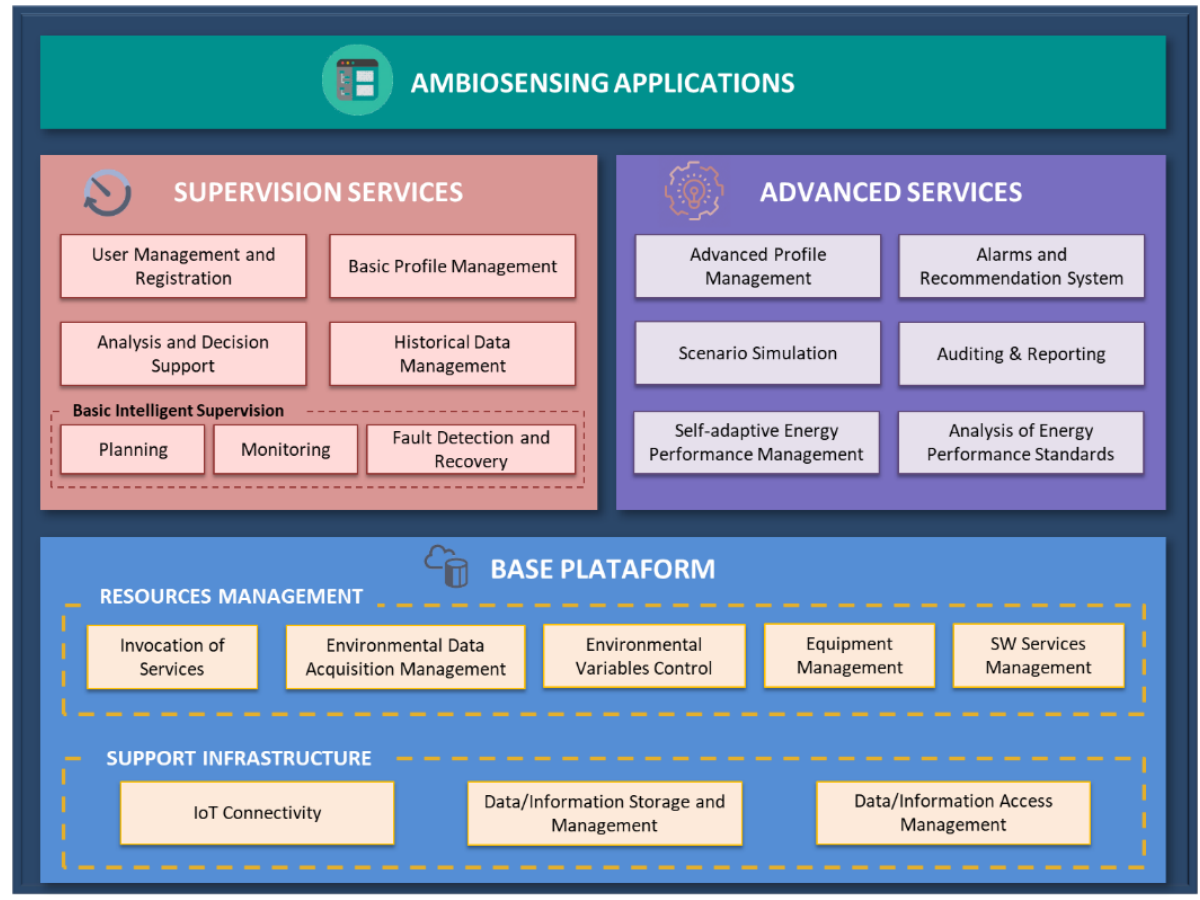

Fig. 2 - Detailed diagram of the Ambiosensing architecture.

Base Platform Layer, which is composed of two sub-layers: the Support Infrastructure Layer and the Resource Management Layer. The main objective is to provide cloud services to support the development and management of IoT functionalities (intelligent networks of sensors and/or remote devices, actuators, devices, automation mechanisms, etc.), materializing digital twins, and the necessary functionalities of the Ambiosensing 
system. Specifically, it aims to support: the installation of sensors and actuators via standard communication protocols and their representation as digital twins; and management services for the processing of large volumes of data from multiple sensors and actuators of various types, such as variable speed drives, luminosity sensors, presence, etc., being all these devices modeled as software service. This layer is also intended to support the storage and management of data/information inherent to the Ambiosensing system as well as access mechanisms to them. The invocation and composition of software services, as well as data collection, control of environmental variables, management of equipment and devices and also the management of existing software services in the Ambiosensing environment, is also included. Through this platform, the various physical components are seen as a community of collaborative digital twins (a kind of collaborative cyber-physical system) [24], which are abstracted through the services they provide and their collaboration capabilities. Fig. 3, illustrates a building floor scenario where several sensor units (assuming that sensors are not intelligent) are physically connected to a single board computer (Ambiosensing intends to adopt the Raspberry Pi model for prototyping) which on its turn makes part of a collaborative network of single board computers which operate in a coordinate way in order to collaboratively compute and communicate raw and/or processed data to the Ambiosensing IoT based platform. Ambiosensing can thus be seen as a collaborative cyber-physical system [25].

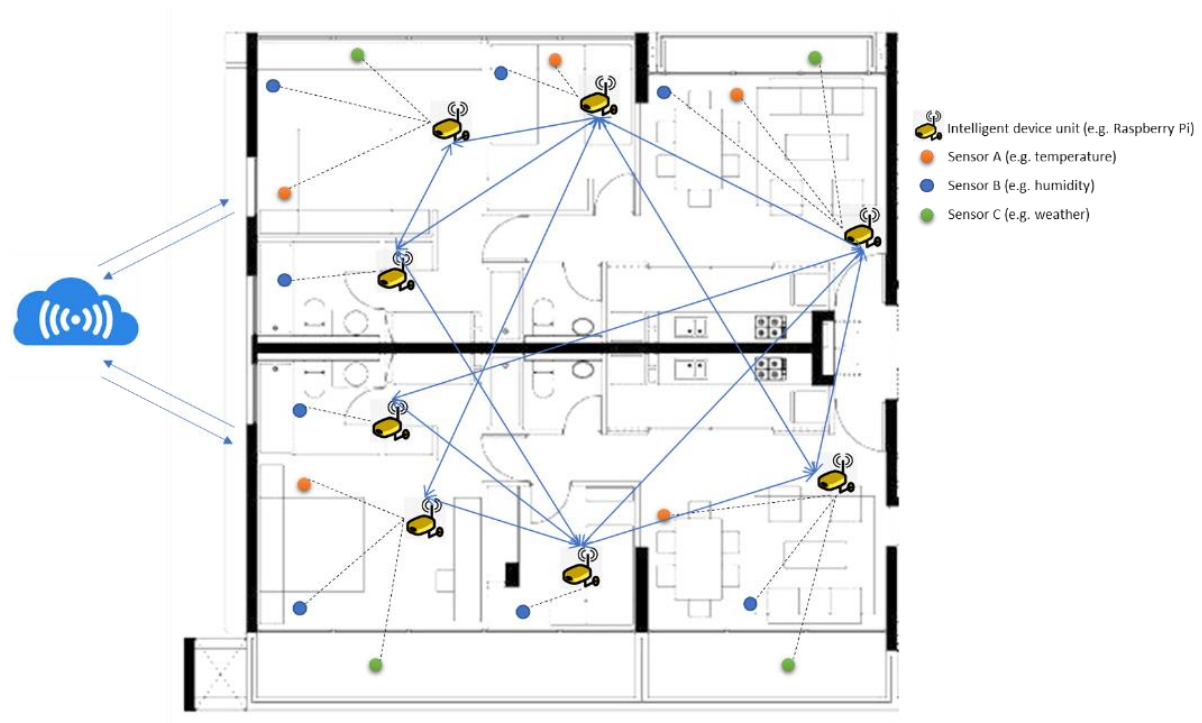

Fig. 3 - An illustration of a collaborative network of intelligent devices of a building floor.

Service Layer, which is composed of two sub-layers at the same conceptual level: the Supervision Services Layer and the Advanced Services Layer. The first aims at providing support services for supervision, analysis and decision support to allow the correct operation of the Ambiosensing system by its users. It must also allow, through 
basic management, the configuration and parameterization of the desired operating profiles. To accomplish this objective, the supervision services shall be capable of monitoring, interpreting and analyzing the correct operation of the Ambiosensing system, considering the normal operating parameters. These parameters must consider the operating profile desired by its users. Authorized users shall be provided with tools to support analysis and decision support considering instantaneous monitoring results and historical data. The advanced services sub-layer has the main objective to provide advanced monitoring and decision-making support services that enhance the proper functioning of the Ambiosensing system, taking into account the composition of the underlying digital twins ecosystem. Based on the acquisition of information, it should be possible to extract knowledge about the proper functioning of space with the Ambiosensing system and adapt its functioning within desirable parameters. To this end, services capable of interpreting the information extracted from the operation of a space with an Ambiosensing system should be developed, verifying its operation and analyzing consumption. Techniques and methodologies of machine learning should be used for the analysis of usage patterns to adapt to the general functioning of the building to improve its efficiency. For this purpose, information visualization mechanisms based on simulation of scenarios may be considered.

Ambiosensing Applications Layer: including interaction applications with the various stakeholders that allow the execution of the use cases previously identified in this paper.

\section{Implementation Aspects}

The proposed architecture presents a set of important aspects that should be highlighted. Such elements are relevant for future instantiations of this architecture and cover three dimensions, namely, (1) technological, (2) strategic, and (3) regulatory and social. For this paper purpose, only a rough description of the technical aspects is explored.

Typically, an energy management ecosystem involves a variety of different technologies. To deal with the inherent complexity, a service-oriented approach (SOA) should be adopted to maintain the desired level of abstraction of the use of functionalities versus their respective implementations. In this way, platforms should, as far as possible, be agnostic about the technologies used.

This heterogeneity of technologies imposes major challenges in terms of interoperability. Typically, in this kind of systems, elements need to work together to be able to satisfy their functionalities, and a good amount of effort is put into programming appropriate interaction mechanisms. Alternatively, to deal with this complexity, it is suggested the development and use of ontologies [22]. Ontologies allow the various elements, involved in an energy efficiency scenario, to share a standardized set of terms for referencing the equipment and its respective control, including the interactions performed by and between the respective services, thus facilitating collaboration among digital twins. Having the services of a platform developed with these ontologies as a reference, any management element in the layer above should be able to interact with the elements below, achieving in this way a level of integration and quasi-agnostic interoperability. For instance, it is intended that 
regardless of its manufacturer, a climate control service will be able to interact with any type of temperature sensor.

The current stage of this ongoing project was validated by our industrial partners and considering its compliance with the identified target application scenarios.

\section{Conclusions and Future Work}

Throughout this work, a description of the proposed conceptual architecture for the energy management of building ecosystems was carried out. This architecture emerges as a response to several factors which are considered simultaneously, namely, the diversity of technological resources that are typically used in efficient energy management systems, the need for these resources to exchange information and the need to work together. Other considered important factors are the challenges underlying the legislation recently approved by the EU in terms of energy efficiency management.

In terms of the developed work, an exhaustive survey of functional requirements was initially carried out, which is briefly represented in the use-case diagram. The proposed architecture is composed of a significant number of elements distributed over three layers, namely, the base platform layer, the services layer, and the application layer.

The architecture elements aim to cope with the functional and non-functional requirements as well as with the EU directives and policies in the area of energy efficiency. For instance, the "Self-adaptive Energy Performance Management" block meets one of the guidelines approved in the EU. The strategy consists in being able to adapt the operating conditions through intelligent services that identify specific circumstances in building divisions and react to them. In this way, the system will be able to adapt and update its operating energy profile to the circumstances detected. Another aspect that is taken into consideration is the current technological trends, such as industry 4.0. In this line, a simulation element is considered [23] [24] due to its potential to, among others, study/anticipate the behavior of simulated systems. The proposed architecture includes an element for the simulation of scenarios, to anticipate the effects of certain management strategies and assess their quality.

The concept of collaborative business ecosystem [23] and the notion of digital twins [24], [25] to represent the physical systems in the cyber space give the base conceptual framework for the proposed system.

As future work, it is intended to instantiate the architecture in collaboration with our industrial partners, building a platform that will be used and tested in a controlled environment for proof of concept of operation of the system.

Acknowledgments. This work was funded in part by the Project AMBIOSENSING Autonomous \& Intelligent Systems for Energy Saving - no . 038253, within the specific scope of the Incentive Scheme for Research and Development - PORTUGAL 2020 launched by $\mathrm{N}^{\circ} 01 / \mathrm{SI} / 2018$. Partial support also comes from the Portuguese FCT Strategic program UID/EEA/00066/2019. 


\section{References}

[1] J. B. / DGEG, "Estratégia para a Eficiencia Energética nos edificios Públicos,” 2015. [Online]. Available: http://www.lneg.pt/download/10887/DGEG_REPublic_ZEB 11dez2015.pdf.

[2] DGEG, "Balanço Energético, sintético," 2016. [Online]. Available: http://www.dgeg.gov.pt/.

[3] V. Masson-Delmotte et al., Global warming of $1.5^{\circ} \mathrm{C}$ An IPCC Special Report. .

[4] C. of the E. Union, "Energy efficient buildings - Presidency secures provisional deal with European Parliament," 2017.

[5] E. Commission, "Clean Energy for All Europeans," European Commission. pp. 1-13, 2016.

[6] U. Nations, "PARIS AGREEMENT," 2015.

[7] European Commission, "Our Vision for A Clean Planet for All," no. November. 2018.

[8] European Parliament, "Directive (EU) 2018/844 of the European Parliament and of the Council of 20 May 2018 amending Directive 2010/31/EU on the energy performance of buildings and Directive 2012/27/EU on energy efficiency," Off. J. Eur. Union, vol. L156, no. 19.6.2018, pp. 75-91, 2018.

[9] I. Gromicho, "Protocolo de Quioto continua a ser essencial para países reduzirem emissões," Ambiente Magazine, p. 1, 16-Nov-2017.

[10] V. Solutions, "ViGIE 2.0." [Online]. Available: https://www.vigiesolutions.com/wpcontent/uploads/2017/09/vigie_pt.pdf.

[11] LEM, "Wi-LEM," 2018. [Online]. Available: https://www.lem.com/en/wilem.

[12] Energy Circle, "SiteSage (Previously eMonitor) Energy Monitor," 2016. [Online]. Available: https://www.energycircle.com/energy-monitors/sitesage-previously-emonitor-energy-monitor.

[13] Optimal Monitoring, "Features of the Optimal Energy Monitoring Software System," 2016. [Online]. Available: http://www.optimalmonitoring.com/system-features/\#toggle-id-3-closed.

[14] Siemens, "Energy Monitoring \& Controlling Solution (EMC)," 2011. [Online]. Available: https://www.downloads.siemens.com/downloadcenter/Download.aspx?pos=download\&fct=getasset\&id1=A6V10328881.

[15] Novalec, "BeEnergy - Monitorização de energia," 2017. [Online]. Available: http://www.novalec.pt/1255/beenergy---monitorizacao-de-energia.htm.

[16] M. Manic, D. Wijayasekara, K. Amarasinghe, and J. J. Rodriguez-Andina, Building Energy Management Systems: The Age of Intelligent and Adaptive Buildings, vol. 10. 2016.

[17] E. Commission, "Smart Finance for Smart Buildings Investment Facility," 2018. [Online]. Available: https://ec.europa.eu/clima/sites/clima/files/docs/pages/initiative_7_smart_en.pdf.

[18] G. J. Levermore, Building Energy Management Systems: An Application to Heating and Control. London: E \& FN Spon, 1992.

[19] P. H. Shaikh, N. B. M. Nor, P. Nallagownden, I. Elamvazuthi, and T. Ibrahim, "A review on optimized control systems for building energy and comfort management of smart sustainable buildings," Renew. Sustain. Energy Rev., vol. 34, pp. 409-429, 2014.

[20] A. Vishwanath, "IoT and Machine Learning to Reduce Energy Use in Cooling Systems," IBM Res. Internet Things, 2018.

[21] General Electrics, "Control Systems," 2018. [Online]. Available: https://www.geautomation.com/products/control-systems.

[22] X. Zhou, Z. Wu, A. Yin, L. Wu, W. Fan, and R. Zhang, "Ontology development for unified traditional Chinese medical language system," Artif. Intell. Med., vol. 32, no. 1, pp. 15-27, 2004.

[23] M. Brettel, N. Friederichsen, M. Keller, and M. Rosenberg, "How virtualization, decentralization and network building change the manufacturing landscape: An Industry 4.0 Perspective," Int. J. Mech. Ind. Sci. Eng., vol. 8, no. 1, pp. 37-44, 2014.

[24] B. Rodič, "Industry 4.0 and the New Simulation Modelling Paradigm," Organizacija, vol. 50, no. 3, pp. 193-207, 2017.

[25] A. Nazarenko, L. M. Camarinha-Matos, "Basis for an Approach to Design Collaborative CyberPhysical Systems". In: Technological Innovation for Industry and Service Systems. DoCEIS 2019. IFIP AICT, vol 553, pp. 193-205. Springer, Cham. DOI: 10.1007/978-3-030-17771-3_16. 